Original Research Article

\title{
Screening and management of retinopathy of prematurity at a tertiary health care centre
}

\author{
Warad C. ${ }^{1}$, Suranagi P.V. ${ }^{2}$, Prasad B.S. ${ }^{3}$ \\ ${ }^{1}$ Dr. Chethana Warad, Assistant Professor, J.N. Medical. College, K.L.E. Academy of Higher Education, Belagavi, Karnataka, \\ ${ }^{2}$ Dr. Prakash V Suranagi, Ex-Head of the Department of Ophthalmology, S.S.I.M.S \& R.C, Davangere, Karnataka. Currently, \\ Specialist Ophthalmology, NMC Royal Medical Centre, Rasal Khaimah, U.A.E., ${ }^{3}$ Dr. B.S. Prasad, Principal and Director of \\ Neonatology, SSIMS \& RC, Davangere, Karnataka, India.
}

Corresponding Author: Dr. Chethana Warad, Assistant Professor, J.N. Medical. College, K.L.E. Academy of Higher Education, Belagavi, Karnataka, India. Email id: cwarad639@gmail.com

\begin{abstract}
Background: Retinopathy of Prematurity is a serious vaso-proliferative disorder that affects premature babies. ROP is a significant cause of childhood blindness unless recognized and treated timely and adequately. Objectives: 1) To determine the magnitude of ROP among premature neonates of less than or equal to 36 weeks of gestational age at SSIMS \& RC, NICU. 2) To determine its association with certain risk factors. 3) To assess the response to laser photocoagulation given to babies with prethreshold ROP type1 and threshold ROP and APROP cases. Materials: 1) All premature neonates of either sex less than or equal to 36 weeks of G.A. 2) Birth weight less than or equal to 2000gm. Methods of data Collection: 1) Place of study: SSIMS \& RC HOSPITAL, LEVEL3 NICU. 2) Duration of study: $1^{\text {st }}$ DEC 2012 to $30^{\text {th }}$ NOV 2013. 3) Sample Size: 110. Results: Out of 110 babies screened for ROP 43 (39.1\%) of them showed signs of ROP in one or both eyes. Statistical analysis showed that incidence of ROP increased as gestational age decreased and also as birth weight decreased. Oxygen therapy, apnoea, RDS, anaemia, blood transfusion, sepsis were found to be significant risk factors. Out of 43 cases with ROP, 13 cases were treated by diode laser. Signs of regression were noted in all 13 cases. Conclusion: The prevalence of ROP in this study was $39.1 \%$, indicating that it is quite a significant cause for childhood blindness. Laser treatment has proved that timely intervention can eliminate blindness due to ROP.
\end{abstract}

Keywords: Childhood blindness, Retinopathy of Prematurity, Neonates

\section{Introduction}

Retinopathy of prematurity is an important cause of preventable blindness. ROP is a disorder of the developing retinal blood vessels in the premature infant retina. The key pathological change in ROP is peripheral retinal neovascularisation. This may regress completely without any sequalae or leave sequale from mild myopia to bilateral total blindness [1-3]. Advances in neonatal care have led to survival of very small babies however a lack of ophthalmic back up to screen all such newborn babies for ROP has resulted in disastrous ocular morbidity and mortality.

Childhood blindness is a curse more so if it occurs immediately after birth. It is important not only in terms of economic burden but also its severe social implications, which is very long in terms of blind years. A well-organized screening strategy and timely intervention can to a large extent prevent blindness due to ROP.

Manuscript received: $4^{\text {th }}$ October 2019

Reviewed: $14^{\text {th }}$ October 2019

Author Corrected: $20^{\text {th }}$ October 2019

Accepted for Publication: $23^{\text {rd }}$ October 2019
The most important determinant of any ROP management program is an effective screening strategy. The use of digital photographic retinal images that are captured and sent for remote interpretation is a developing approach to ROP screening. Timely intervention for ROP is effective at preventing severe vision impairment.

\section{Material and Methods}

Source of data: All premature neonates of either sex less than or equal to 36 weeks of gestational age and babies with birth weight less than or equal to 2000 gram at S.S.I.M.S \& R.C , N.I.C.U, Davangere were taken as source of data.

\section{Inclusion criteria}

1. Babies born at $</=36$ weeks of gestational age

2 . Babies born with birth weight $</=2000$ grams

3. Special criteria: to include premature babies with other risk factors like sepsis, multiple blood transfusions, R.D.S, extraordinary oxygen support, apnoea with other 


\section{Original Research Article}

risk factors like sepsis, multiple blood transfusions, R.D.S, extraordinary oxygen support, apnoea with bag / mask ventilation / bradycardia, shock, hypercarbia/ hypocarbia, jaundice, PDA, IVH, Postnatal steroids.

\section{Exclusion criteria}

1. Babies born at $>36$ weeks of gestational age.

2. Babies with birth weight $>2000$ gram without risk factors

3. Premature babies with lesions other than R.O.P such as Retinal haemorrhage, congenital coloboma, chorioretinitis and other such lesions.

Sample size and design: A total of 110 babies were screened in the present study. Babies admitted to S.S.I.M.S \& R.C, N.I.C.U, who fulfilled the above criteria were included in the study.

It is a hospital based descriptive study.

Study period: Study was carried out between $1^{\text {st }}$ December 2012 to $30^{\text {th }}$ April 2014.

Statiscal Analysis: Analysis was performed using SPSS version 16.0. Univariate analysis was conducted using Chi square test.

Ethical clearance was obtained from the hospital ethics committee and informed consent of the parents was also obtained.

\section{Results}

The study was conducted from $1^{\text {st }}$ December 2012 to $30^{\text {th }}$ April 2014. During the study period a total of 110 babies were screened for ROP and 43 (39.1\%) of them were found to be positive. Our results were analyzed against the following variables:

Gestational age, Birth weight, Sex, Oxygen therapy, RDS, Apnoea, Sepsis, Anaemia, Thrombocytopenia, Blood transfusion, Multiple births, Hyperbilirubinemia. All the results were subjected to Chi square test to find whether the association was significant or not.

Incidence of ROP: Out of 110 babies screened for ROP 43 (39.1\%) of them turned out to be ROP positive. Table 1 shows the incidence of ROP distribution.

Table-1: Incidence of ROP.

\begin{tabular}{|c|c|c|}
\hline ROP & Frequency & Percent \\
\hline Present & 43 & 39.1 \\
\hline Absent & 67 & 60.9 \\
\hline Total & $\mathbf{1 1 0}$ & $\mathbf{1 0 0 . 0}$ \\
\hline
\end{tabular}

ROP and Gender: In a total of 110 babies 55 babies were Males and rest 55 were Females. In 43 positive cases there were 24 male babies and 19 female babies. Table 2 shows the gender distribution in ROP. Gender is not a statistically significant risk factor according to this study. 
Table-2: Gender and ROP

\begin{tabular}{|c|c|c|c|c|}
\hline & & Positive cases & Negative cases & 55 \\
\hline Male & Number & 24 & 31 & $50.0 \%$ \\
\hline Female & $\%$ & $55.8 \%$ & $46.3 \%$ & 55 \\
\hline & Number & 19 & 36 & $50.0 \%$ \\
\hline Total & Number & $44.2 \%$ & $63.7 \%$ & 110 \\
\hline \multicolumn{2}{|c|}{$\%$} & 43 & $100.0 \%$ & $100.0 \%$ \\
\hline Chi square $=0.95$ & p value $=0.32$ & $100.0 \%$ & & \\
\hline
\end{tabular}

ROP and Gestational age: In the present study the incidence of ROP in babies with gestational age $<$ or $=36 \mathrm{weeks}$ is $53.5 \%$, in those between 25 to 30 weeks and $41.9 \%$ in those between $31-33$ weeks and $4.7 \%$ in those between 34 to 36 weeks. So, in the present study, increased incidence is seen as the gestational age decreased. Table 3 shows the statistics in detail with regards to the gestational age and ROP.

Table-3: Gestational age and ROP.

\begin{tabular}{|c|c|c|c|c|}
\hline Gestational age & & Positive cases & Negative cases & \\
\hline $25-30$ & Number & 23 & 12 & 35 \\
\hline & $\%$ & $53.5 \%$ & $17.9 \%$ & $31.8 \%$ \\
\hline $31-33$ & Number & 18 & $62.7 \%$ & $54.5 \%$ \\
\hline $34-36$ & $\%$ & $41.9 \%$ & 13 & 15 \\
\hline & Number & 2 & $67 \%$ & $13.6 \%$ \\
\hline Total & Number & $4.7 \%$ & $100.0 \%$ & $100.0 \%$ \\
\hline & $\%$ & $100.0 \% \quad 13$ & & \\
\hline
\end{tabular}

ROP and Birth Weight: In the present study birth weight ranged from 740 to $2500 \mathrm{gm}$. Low birth weight is a statistically significant risk factor for development of ROP. Table 4 shows birth weight distribution in ROP.

Table 4: Birth Weight and ROP.

\begin{tabular}{|c|c|c|c|c|}
\hline Birth weight & & Positive cases & Negative cases & Total \\
\hline $740-1000$ & Number & 5 & 2 & 7 \\
\hline & $\%$ & $11.6 \%$ & $3.0 \%$ & $4.4 \%$ \\
\hline $1001-1500$ & Number & 26 & 19 & $40.9 \%$ \\
\hline $1501-2000$ & $\%$ & $60.5 \%$ & $28.4 \%$ & 55 \\
\hline & Number & 12 & $64.2 \%$ & $50.0 \%$ \\
\hline $2001-2500$ & Number & $27.9 \%$ & 3 & 3 \\
\hline & $\%$ & 0 & $4.5 \%$ & $2.7 \%$ \\
\hline & Number & 43 & 67 & 110 \\
\hline & $\%$ & $100.0 \%$ & $100.0 \%$ & $100.0 \%$ \\
\hline
\end{tabular}

ROP and Oxygen therapy: In the present study out of 43 babies, 30 babies (69.8\%) who received oxygen developed ROP. Babies (13) who did not receive oxygen also developed ROP. However, there is significant association of ROP with oxygen therapy as shown in Table 5 . 
Table-5: Oxygen therapy and ROP Outcome.

\begin{tabular}{|c|c|c|c|c|}
\hline Oxygen & & Positive cases & Negative Cases & 11 \\
\hline Given & Number & 30 & $16.4 \%$ & 41 \\
\hline & $\%$ & $69.8 \%$ & 56 & $37.3 \%$ \\
\hline Not given & Number & 13 & $83.6 \%$ & 69 \\
\hline & $\%$ & $30.2 \%$ & 67 & 110 \\
\hline Total & Number & 43 & $100.0 \%$ & $100.0 \%$ \\
\hline & $\%$ & $100.0 \%$ & $\mathrm{p}$ value $=0.00$ \\
\hline
\end{tabular}

Apnoea and ROP: Out of 110 babies, 12 of them had apnoea, out of these 12, 8 of them had ROP. It was found to be statistically significant as shown in Table 6 .

Table-6: Apnoea and ROP.

\begin{tabular}{|c|c|c|c|c|}
\hline Apnea & & Positive cases & Negative cases & \\
\hline Present & Number & 8 & 4 & 12 \\
\hline & $\%$ & $18.6 \%$ & $6.0 \%$ & $10.9 \%$ \\
\hline Not present & Number & 35 & 63 & 98 \\
\hline & $\%$ & $81.4 \%$ & 67 & 110 \\
\hline Total & Number & 43 & $100.0 \%$ & $100.0 \%$ \\
\hline & $\%$ & $100.0 \% \quad$ phi square $=4.30 \quad \mathrm{p}$ value $=0.03$ \\
\hline
\end{tabular}

Respiratory Distress Syndrome and ROP: Out of 48 cases who had RDS, 32 babies had ROP. This was found to be statistically significant as shown in Table 7.

Table-7: RDS and ROP.

\begin{tabular}{|c|c|c|c|c|}
\hline RDS & & Positive cases & Negative cases & \\
\hline Present & Number & 32 & 16 & 48 \\
\hline & $\%$ & $74.4 \%$ & $23.9 \%$ & $43.6 \%$ \\
\hline Not Present & Number & 11 & 51 & 62 \\
\hline & $\%$ & $25.6 \%$ & $76.1 \%$ & 110 \\
\hline Total & Number & 43 & $100.0 \%$ & $100.0 \%$ \\
\hline & \multicolumn{2}{c}{ Chi square $=27.19 \quad \mathrm{p}$ value $=0.00$} \\
\hline
\end{tabular}

Anaemia and ROP: Out of 110 babies 19 had Anaemia and 13 babies out of those 19 had ROP. This is a highly significant association with ROP as shown in Table 8.

Table-8: Anaemia and ROP.

\begin{tabular}{|c|c|c|c|c|}
\hline Anemia & & Positive cases & Negative cases & 6 \\
\hline Present & Number & 13 & $9.0 \%$ & 19 \\
\hline & $\%$ & $30.2 \%$ & 61 & 91 \\
\hline Not present & Number & 30 & $91.0 \%$ & $82.7 \%$ \\
\hline Total & $\%$ & $69.8 \%$ & 67 & 110 \\
\hline & Number & 43 & $100.0 \%$ & $100.0 \%$ \\
\hline & $\%$ & $100.0 \% \quad$ Chi square $=8.29 \quad \mathrm{p}$ value $=0.00$ \\
\hline
\end{tabular}

Thrombocytopenia and ROP: Out of 18 babies who had thrombocytopenia, 10 (23.3\%) of them had ROP. This was statistically not found to be a significant risk factor as shown in Table 9. 
Table-9: Thrombocytopenia and ROP

\begin{tabular}{|c|c|c|c|c|}
\hline Thrombocytopenia & & Positive cases & Negative cases & \\
\hline Present & Number & 10 & 8 & 18 \\
\hline & $\%$ & $23.3 \%$ & 59 & $16.4 \%$ \\
\hline Not present & Number & 33 & $88.1 \%$ & $83.6 \%$ \\
\hline Total & $\%$ & $76.7 \%$ & 67 & 110 \\
\hline & Number & 43 & $100.0 \%$ & $100.0 \%$ \\
\hline & $\%$ & $100.0 \%$ & & \\
\hline
\end{tabular}

Blood transfusion and ROP: Out of 20 babies who received blood transfusion $13(30.2 \%)$ of them had ROP. This was a statistically significant risk factor for ROP as shown in Table 10.

Table-10: Blood transfusion and ROP.

\begin{tabular}{|c|c|c|c|c|}
\hline Blood transfusion & & Positive cases & Negative cases & \\
\hline Given & Number & 13 & 7 & 20 \\
\hline & $\%$ & $30.2 \%$ & 60 & $18.2 \%$ \\
\hline Not given & Number & 30 & $89.6 \%$ & 90 \\
\hline Total & $\%$ & $69.8 \%$ & 67 & $11.8 \%$ \\
\hline & Number & 43 & $100.0 \%$ & $100.0 \%$ \\
\hline
\end{tabular}

Sepsis and ROP: Sepsis is a statistically significant risk factor for ROP according to this study as shown in Table 11.

Table-11: Sepsis and ROP

\begin{tabular}{|c|c|c|c|c|}
\hline Sepsis & & ROP Positive & ROP Negative & \\
\hline Present & Number & 19 & 12 & 31 \\
\hline & $\%$ & $44.2 \%$ & $17.9 \%$ & $28.2 \%$ \\
\hline Not present & Number & 24 & 55 & 79 \\
\hline & $\%$ & $55.8 \%$ & $82.1 \%$ & $71.8 \%$ \\
\hline Total & Number & 43 & $100.0 \%$ & $100 \%$ \\
\hline \multicolumn{2}{|l|}{$\%$} & $100.0 \%$ & & \\
\hline Chi square $=8.93 \quad \mathrm{p}$ value $=0.003$ & & & \\
\hline
\end{tabular}

Multiple births and ROP: Out of 29 Multiple birth cases, 13(30.2\%) babies had ROP. This was not found to be statistically significant according to present study as shown in Table 12.

Table-12: Multiple births and ROP

\begin{tabular}{|c|c|c|c|c|}
\hline Multiple births & & Positive cases & Negative cases & \\
\hline Present & Number & 13 & 16 & 29 \\
\hline & $\%$ & $30.2 \%$ & $23.9 \%$ & $26.4 \%$ \\
\hline not present & Number & 30 & 51 & $73.1 \%$ \\
\hline Total & $\%$ & $69.8 \%$ & 67 & 110 \\
\hline & Number & 43 & $100.0 \%$ & $100.0 \%$ \\
\hline
\end{tabular}

Hyperbilirubinemia and ROP: Out of 30 babies who had hyperbilirubinemia 12 (27.9\%) of them had ROP. This was not found to be a statistically significant factor according to the present study $\mathrm{p}=0.90$ as shown in Table 13 . 
Original Research Article

Table-13: Hyperbilirubinemia and ROP

\begin{tabular}{|c|c|c|c|c|}
\hline Hyperbilirubinemia & & Positive cases & Negative cases & \\
\hline Present & Number & 12 & 18 & 30 \\
\hline & $\%$ & $27.9 \%$ & $26.9 \%$ & $27.3 \%$ \\
\hline Not present & Number & 31 & 49 & 80 \\
\hline & $\%$ & $72.1 \%$ & $73.1 \%$ & $72.7 \%$ \\
\hline Total & Number & 43 & 67 & 110 \\
\hline \multicolumn{5}{|c|}{ Chi square $=0.01 \quad p$ value $=0.90$} \\
\hline
\end{tabular}

Outcome of Laser treatment for ROP: Laser treatment is proved to be very effective in regressing ROP in all cases. Results of laser treatment as shown in Table 14.

Table-14: laser treatment outcome

\begin{tabular}{|c|c|c|c|c|}
\hline Treatment plan & & Positive cases & Negative cases & \\
\hline Given & Number & 13 & 0 & 13 \\
\hline & $\%$ & $30.2 \%$ & $.0 \%$ & $11.8 \%$ \\
\hline Not given & Number & 30 & 67 & 97 \\
\hline & $\%$ & $69.8 \%$ & $100.0 \%$ & $88.2 \%$ \\
\hline Total & Number & 43 & 67 & 110 \\
\hline & $\%$ & $100.0 \%$ & $100.0 \%$ & $100.0 \%$ \\
\hline \multicolumn{2}{r|}{ Chi square $=22.97 \quad \mathrm{p}$ value $=0.00$} \\
\hline
\end{tabular}

\section{Discussion}

The condition was first described by Terry in 1942 as retro lental fibroplasias. The term ROP was coined by Heath in 1951 . ROP is a multifactorial vasoproliferative retinal disorder. It occurs in somewhat overlapping phases 1) An acute phase in which normal vasculogenesis is interrupted and a response to the injury is observable in the retina.

2) A chronic or late proliferation of membranes into the vitreous during which tractional detachment of the retina, ectopia and scarring of the macula occur and cause significant visual loss [4-7].

Growth factors in R.O.P: Vasoformative factors play a vital role in the normal development of retinal vasculature especially vascular endothelial growth factor [VEGF] was among first to be identified and cloned. VEGF is produced anterior to the vascular area. Adequate amount of VEGF is required for retinal growth. If the avascular zone is larger and when this is exposed to the hyperoxic state, VEGF expression is decreased leading to vasobliteration. This causes hypoxia and ischemia in nonperfused area if insult is sustained. This again stimulates VEGF production and thus neovascularization, over this time if VEGF production decreases, ROP will regress. If VEGF production increase or persist, ROP will progress. The manipulation of these factors could be beneficial therapeutically [1].

In the present study, screening of babies admitted to NICU with birth weight $\leq 2000 \mathrm{gm}$ and / or gestational age $\leq 36$ weeks was done. The scenario in developing countries is quite different. Larger and gestationally older infants are more likely to develop ROP compared to their counterparts in western countries. Hence the application of western screening guidelines for the developing countries has been questioned by Jalali et al [8]. As a higher cut off limit, Jalali et al have recommended screening babies born at $\leq 37$ weeks G.A and/or birth weight $2000 \mathrm{gm}$ in the presence of a high sickness score in order to prevent missing any infant with threshold ROP.

Incidence: In the present study incidence of ROP was 39.1\%. The reported incidence of ROP in studies done by Chaudhari s et al [9], Gupta VP et al [10], Aggarval et al [11], and Varugheses et al [12], the incidence rates were 22.3\%, 21.7 \%, 32\%, 52\% respectively. 
Original Research Article

Sex distribution: Though the incidence of ROP was more in males $(55.8 \%)$ than females $(44.2 \%)$ it was statistically found to be not significant. ( $\mathrm{P}=0.13)$. A study done by MB Yang concluded that there were no racial or gender differences in severity of ROP [13].

\section{Association with risk factors:}

ROP and gestational age: The major ROP risk factor is the degree of immaturity as measured by either Birth weight or Gestational age. The lower the birth weight the higher the risk of disease. The smaller the neonate, the more immature is retinal vasculature and the larger the retinal vascular area. For everyone week decrease in gestational age there was twice the time increased risk of nasal origin of ROP.

Incidence of ROP increased as gestational age decreased. The results correlated with studies done by Rekha $\mathrm{S}$ et al [14] who found that the incidence of ROP among 28-29 weeks, 30-31 weeks, $32-33$ weeks of G.A was $83 \%, 60 \%$ and $50 \%$ respectively. In the present study, it has been proved that the incidence and severity of ROP are closely related to lower birth weight and lower post conceptional age.

ROP and Birth weight: In the present study, it was observed that a significant correlation between birth weight and ROP $(\mathrm{P}=0.00)$. Lower the birth weight higher is the risk of developing ROP.

ROP and oxygen: Campbell was the first to suggest that supplemental oxygen was the cause for the sudden increase in the numbers of infants developing retrolental fibroplasia in the early 1940s. Saito et al concluded that extremely premature infants with widely fluctuating arterial oxygen probably have a higher risk of developing progressive ROP [2].

In the present study there was a significant correlation between oxygen supplementation and ROP $(\mathrm{P}=0.00)$. So, there should be cautious use of oxygen supplementation in NICU.

ROP and Apnoea: A higher occurrence of apnoeic episodes requiring bagging and hypoxemia were found among infants with severe R.O.P [3].

In the present study, apnoea was found to be significant risk factor. ( $\mathrm{p}=0.03$ ). Studies done by Aggarwal R et al [11], Gupta VP et al [10], Chaudhary $\mathrm{S}$ et al [9] concluded apnoea as a significant risk factor for ROP.

ROP and RDS: In the present study there was a significant correlation between RDS AND ROP, the same has been supported by studies done by Gupta et al and others have found ROP in babies with RDS [10].

ROP and Anemia: Neonates with anaemia are at increased risk of ROP. It was also suggested that a haematocrit less than $40 \%$ should be taken as a cut off for anaemia rather than taking the haemoglobin values as reference [7].

In the present study anemia was found to be a significant risk factor $(\mathrm{p}=0.00)$. Studies done by Rekha $\mathrm{S}$ et al and several others have also found that Preterm infants given blood transfusions receive adult haemoglobin [14]. As the latter binds oxygen less avidly than fetal haemoglobin the oxygen dissociation curve is shifted so that more oxygen is delivered up rendering tissues relatively hyperoxic. This could increase the risk of ROP [5]. Hence Anemia is considered as a significant risk factor.

ROP and Blood transfusion: In the present study blood and blood products transfusion is proven to be a significant risk factor for ROP development $(\mathrm{p}=0.00)$. Similarly, other studies done by Clark et al, Cooke et al have found blood transfusion as a significant risk factor for the development of ROP $[15,16]$. Acidosis is a powerful vasodilator stimulus and plays a major role in cerebral blood flow regulation. It has also been shown to be associated with development of intraventricular haemorrhage. Acidosis and the number of times the blood PH was less than 7.2 were significant risk factors of R.O.P according to study done by Prendiville A et al [4].

ROP and Sepsis: Combined risk of bacterial and fungal sepsis is significantly associated with severe ROP. The effect of sepsis on ROP is proposed to be cytokine or endotoxin mediated or due to the oxidative burst in the neutrophils soon after the infection prevention and early control of sepsis can reduce the risk of ROP. In the present study sepsis is found to be a significant risk factor for ROP $(\mathrm{P}=0.03)$. Similarly, studies done by Kavurt S [17], Mittal et al [18] have found that presence of sepsis is one of the significant risk factors for ROP. 


\section{Original Research Article}

Multiple births and ROP: Although multiple births per se does not increase the risk of developing ROP and concordant twins behave similarly, it has been reported that for discordant twins the smaller baby has a greater risk of developing this condition [6]. According to the present study multiple births is not a significant risk factor for ROP.

Laser treatment outcome of ROP: Out of 43 cases found to have ROP of various stages, 13 babies required treatment. In those 13 , two were found to have APROP and were treated with first sitting of laser photocoagulation within $24 \mathrm{hrs}$ followed by second sitting within a week following laser treatment signs of regression were seen in both the babies. In the remaining 7 babies with various stages of ROP who required treatment were given laser photocoagulation in 2 sittings, 3 babies received laser photocoagulation in 3 sittings, 1 baby received laser photocoagulation in one sitting, following treatment signs of regression were found in all these cases. So, treatment outcome of ROP in the present study was $100 \%$ (Table 15 and Table 16). In agreement with Coats et al, it was found that the six cases that required laser intervention improved and ROP regressed with regular follow up. Laser is now the preferred mode since the most severe forms of the disease are more easily treated with laser than cryotherapy.

Table 15: Frequency distribution of stages of ROP in R.E.

\begin{tabular}{|c|c|c|}
\hline Stages & Number of cases & Percent \\
\hline No stage & 68 & 61.8 \\
\hline Stage 1 & 16 & 14.5 \\
\hline Stage2 & 21 & 19.1 \\
\hline Stage3 & 3 & 2.7 \\
\hline Stage 4 & 0 & 0 \\
\hline Stage 5 & 0 & 0 \\
\hline APROP & 2 & 1.8 \\
\hline Total & $\mathbf{1 1 0}$ & $\mathbf{1 0 0 . 0}$ \\
\hline
\end{tabular}

Table 16: Frequency distribution of stages of ROP in L.E.

\begin{tabular}{|c|c|c|}
\hline & Frequency & Percent \\
\hline No stage & 67 & 60.9 \\
\hline Stage 1 & 20 & 18.2 \\
\hline Stage2 & 16 & 14.5 \\
\hline Stage3 & 4 & 3.6 \\
\hline Stage4 & 1 & .9 \\
\hline Stage 5 & 0 & 0 \\
\hline APROP & 2 & 1.8 \\
\hline Total & $\mathbf{1 1 0}$ & $\mathbf{1 0 0 . 0}$ \\
\hline
\end{tabular}

Laser photocoagulation is an established technique for the treatment of ROP. At present, the standard of care in ROP is the diode red laser indirect ophthalmoscope. Laser indeed has many advantages over cryotherapy like less post treatment pain, adnexal edema, exudative retinal detachment, vitreo retinal traction and vitreous hemorrhage due to reduced break down of the blood retinal barrier. The limitations of the present study were the number of patients included in the study population.

\section{Conclusion}

In conclusion, the prevalence of ROP in this study was $39.1 \%$, the data of this study suggests that low gestational age, sepsis, low birth weight, oxygen therapy, apnoea, RDS, anemia, blood transfusion are independent risk factors in the development of ROP. Clinicians should be aware of the presence of the additional risk factors when monitoring preterm infants. The analysis of risk factors for ROP development will help to understand and predict it in severe preterm infants.

\section{What the study adds to the existing knowledge?}

The most important determinant of any ROP management program is an effective screening strategy. The use of digital photographic retinal images that are captured and sent for remote interpretation is a developing approach to ROP screening. A well-organized screening strategy and timely intervention can to a large extent prevent blindness due to ROP. 


\section{Author's contribution}

Dr. Chethana Warad: Concept, study design, manuscript preparation

\section{Dr. Prakash V Suranagi: Manuscript preparation}

Dr. B.S. Prasad: Manuscript preparation

Acknowledgement: Special thanks to the chairman Shri S.S. Mallikarjun, SSIMS\&RC, Davangere.

Special thanks to the principal Dr B.S. Prasad, DCH, MD, MRCP (U.K), FRCPCH (UK), CCT(UK), Principal and Director of Neonatology for supporting us to do this work.

Authors would like to thank Dr Anand Vinekar, Narayana Nethralaya, Banglore for their brainchild, KIDROP which has helped screen and treat thousands of babies across the state. Authors are indebted to Mr Madhav Padki and Mr Someshwar for their technical assistance.

The nurses of NICU who take special care of the neonates are truly worthy of a mention. Lastly, authors would like to profusely thank all the mothers for giving us consent to screen their babies, provide care for them and making this study successful.

Funding: No funding sources

Conflict of interest: None declared

Ethical Approval: This study was approved by the Institutional Ethics Committee

\section{Reference}

1. Azad RV. Retinopathy of prematurity: A text and atlas. Jaypee Brothers; 2006.

2. Saito Y, Omoto T, Cho Y, Hatsukawa Y, Fujimura M, Takeuchi T. The progression of retinopathy of prematurity and fluctuation in blood gas tension. Graefe's Arch Clin Exp Ophthalmol. 1993;231(3):151-156.

3. Gunn TR, Easdown J, Outerbridge EW, Aranda JV. Risk factors in retrolental fibroplasia. Pediat. 1980;65(6):10961100 .

4. Prendiville A, Schulenburg WE. Clinical factors associated with retinopathy of prematurity. Arch Dis Child. 1988;63(5):522-527.

5. Brooks SE, Marcus DM, Gillis D, Pirie E, Johnson MH, Bhatia J. The effect of blood transfusion protocol on retinopathy of prematurity: a prospective, randomized study. Pediatr. 1999;104(3):514-518.
6. Fellows RR, McGregor ML, Bremer DL, Rogers GL, Miller D. Retinopathy of prematurity in discordant twins. J Pediat Ophthalmol Strabis. 1995;32(2):86-88.

7. Englert JA, Saunders RA, Purohit D, Hulsey TC, Ebeling $M$. The effect of anaemia on retinopathy of prematurity in extremely low birth weight infants. J Perinatol. 2001; 21(1):21-26. doi: 10.1038/sj.jp.7200511.

8. Jalali S, Azad R, Trehan HS, Dogra MR, Gopal L, Narendran V. Technical aspects of laser treatment for acute retinopathy of prematurity under topical anesthesia. Indian J Ophthalmol. 2010;58(6):509-515. doi: 10.4103/03014738. 71689.

9. Chaudhari S, Patwardhan V, Vaidya U, Kadam S, Kamat A. Retinopathy of prematurity in a tertiary care centreincidence, risk factors and outcome. Indian Pediatr. 2009; 46 (3):219-224.

10. Gupta VP, Dhaliwal U, Sharma R, Gupta P, Rohatgi J. Retinopathy of prematurity risk factors. Indian $\mathrm{J}$ Pediatr 2004;71(10):887-892.

11. Aggarwal R, Deorari AK et al. Changing profile of retinopathy of prematurity. J Trop Pediatr. 2002;48(4):239242. doi: 10.1093/tropej/48.4.239.

12. Varughese S, Jain S, Gupta N, Singh S, Tyagi V, Puliyel JM. Magnitude of the problem of retinopthy of prematurity experience in a large maternity unit with a medium size level-3 nursery. Indian J Ophthalmol. 2001; 49 (3): 187-188.

13. Yang MB, Donovan EF, Wagge JR. Race, Gender and Clinical Risk Index for Babies (CRIB) Score as Predictors of Severe Retinopathy of Prematurity. J AAPOS. 2006;10 (3):253-261. doi: https://doi.org/10.1016/j.jaapos. 2006.01. 004 .

14. Rekha S, Battu RR. Retinopathy of prematurity: incidence and risk factors. Indian Pediatr 1996;33(12):9991003.

15. Clark C, Gibbs JA, Maniello R, Outerbridge EW, Aranda JV. Blood Transfusion: a possible risk factor in retrolental fibroplasia. Acta Pediatr Scand. 1981;(70):535539. doi: https:// doi. org/ 10.1111/j.1651-2227.1981.tb 05736.x

16. Cooke RW, Drury JA, Yoxall CW, James C. Blood transfusion and chronic lung disease in preterm infants. Europe J Pediat. 1996;156(1):47-50. doi: 10.1007/ s00431 0050551. 


\section{Original Research Article}

17. Kavurt S, Özcan B, Aydemir O, Bas AY, Demirel N. Risk of Retinopathy of Prematurity in Small for Gestational Age Premature Infants. Indian Paediat. 2014; 51(10): 804-806
18. Mittal M, Dhanireddy R, Higgins RD. Candida sepsis and association with retinopathy of prematurity. Pediat. 1998; 101(4 Pt 1):654-657.

\section{How to cite this article?}

Warad C, Suranagi P.V, Prasad B.S. Screening and management of retinopathy of prematurity at a tertiary health care centre. Trop J Ophthalmol Otolaryngol.2019;4(7):425-434.doi:10.17511/jooo.2019.i07.05 